\title{
Different effects of isolation-rearing and neonatal MK-801 treatment on attentional modulations of prepulse inhibition of startle in rats
}

\author{
Zhe-Meng $\mathrm{Wu}^{1} \cdot$ Yu Ding ${ }^{1} \cdot$ Hong-Xiao $\mathrm{Jia}^{2,3} \cdot \operatorname{Liang} \mathrm{Li}^{1,3}$
}

Received: 3 February 2016 / Accepted: 2 June 2016

(C) Springer-Verlag Berlin Heidelberg 2016

\begin{abstract}
Rational Prepulse inhibition (PPI) is suppression of the startle reflex by a weaker sensory stimulus (prepulse) preceding the startling stimulus. In people with schizophrenia, impairment of attentional modulation of PPI, but not impairment of baseline PPI, is correlated with symptom severity. In rats, both fear conditioning of prepulse and perceptually spatial separation between the conditioned prepulse and a noise masker enhance PPI (the paradigms of attentional modulation of PPI).

Objectives As a neurodevelopmental model of schizophrenia, isolation rearing impairs both baseline PPI and attentional modulations of PPI in rats. This study examined in SpragueDawley male rats whether neonatally blocking $N$-methyl-Daspartate (NMDA) receptors specifically affects attentional modulations of PPI during adulthood.

Results Both socially reared rats with neonatal exposure to the NMDA receptor antagonist MK-801 and isolation-reared rats exhibited augmented startle responses, but only isolation rearing impaired baseline PPI. Fear conditioning of the prepulse enhanced PPI in socially reared rats, but MK-801-treated rats lost the prepulse feature specificity. Perceptually spatial
\end{abstract}

Hong-Xiao Jia

jhxlj@vip.163.com

$\triangle$ Liang Li

liangli@pku.edu.cn

1 Department of Psychology and Beijing Key Laboratory of Behavior and Mental Health, Speech and Hearing Research Center, Key

Laboratory on Machine Perception (Ministry of Education), Peking

University, Beijing 100080, China

2 Beijing Key Laboratory for Mental Disorders, Center of Schizophrenia,Beijing Anding Hospital, Capital Medical University, Beijing 100088, China

3 Beijing Institute for Brain Disorders, Beijing, China separation between the conditioned prepulse and a noise masker further enhanced PPI only in normally reared rats. Clozapine administration during adulthood generally weakened startle, enhanced baseline PPI in neonatally interrupted rats, and restored the fear conditioning-induced PPI enhancement in isolation-reared rats with a loss of the prepulse feature specificity. Clozapine administration also abolished both the perceptual separation-induced PPI enhancement in normally reared rats and the fear conditioning-induced PPI enhancement in MK-801-treated rats.

Conclusions Isolation rearing impairs both baseline PPI and attentional modulations of PPI, but neonatally disrupting NMDA receptor-mediated transmissions specifically impair attentional modulations of PPI. Clozapine has limited alleviating effects.

Keywords Attentional modulation · Animal model · Clozapine · Isolation rearing · Neonatal MK-801 exposure · Prepulse inhibition $\cdot$ Schizophrenia $\cdot$ Fear conditioning · Precedence effect $\cdot$ Perceived spatial separation

\section{Introduction}

Prepulse inhibition (PPI) is the normal reduction of the amplitude of the startle reflex in response to an intense startling stimulus (pulse) when this intense stimulus is shortly preceded by a weaker, non-startling sensory stimulus (prepulse; Fendt et al. 2001; Ison and Hammond 1971; Li et al. 2009). PPI can be enhanced by selective attention to the prepulse stimulus in both humans and rats ( $\mathrm{Li}$ et al. 2009). For example, when a prepulse becomes fear conditioned, the conditioned prepulse, but not a conditioning-control prepulse, elicits enhanced PPI, indicating that the fear conditioning-induced PPI enhancement exhibits prepulse feature specificity (Du et al. 2009, 
2010, 2011; Zou et al. 2007). PPI can also be enhanced by spatial attention (see below).

In a reverberant environment, listeners with normal hearing have the ability to perceptually integrate the direct sound wave and the reflections of the sound source: attributes of the delayed and correlated reflections are perceptually captured by the direct sound wave ( $\mathrm{Li}$ et al. 2005), leading to a single fused image whose perceived point of origin is around the location of the leading source. This auditory phenomenon is called the "precedence effect" (for reviews, see Freyman et al. 1999; Li et al. 2009; Litovsky et al. 1999). In humans, when both a target sound and a masker are presented by each of the two spatially separated loudspeakers with an inter-loudspeaker delay of $3 \mathrm{~ms}$, due to the precedence effect, only a single target image is perceived as coming from the leading loudspeaker for the target. Also, only a single masker image is perceived as coming from the leading loudspeaker for the masker. Recognizing the target under the condition of perceived target-masker spatial separation (when the leading loudspeaker is different between target and masker) is significantly better than that under the condition of perceived co-location between target and masker (when the leading loudspeaker is the same for both target and masker; Li et al. 2009). Note that shifts between the perceived separation condition and the perceived co-location condition do not substantially change the signal-to-masker ratio in sound pressure level and the sound image compactness/diffusiveness (Li et al. 2004, 2009).

In rats, with the mediation of the posterior parietal cortex (PPC; Du et al. 2011), when a fear-conditioned prepulse and a noise masker are delivered by each of the two spatially separated loudspeakers with an inter-loudspeaker delay of $1 \mathrm{~ms}$, the precedence effect-induced perceived spatial separation between the conditioned prepulse and the noise masker further enhances PPI by facilitating spatial attention to the prepulse (Du et al. 2009, 2010, 2011). This perceptual spatial separation-induced PPI enhancement also exhibits the prepulse feature specificity (Du et al. 2009, 2010).

People with schizophrenia exhibit impairments in both baseline PPI (Geyer et al. 2001) and attentional modulations of PPI (Hazlett et al. 2007). Interestingly, impairment of attentional modulation of PPI, but not of baseline PPI, is correlated with symptom severity of schizophrenia (Hazlett et al. 2007). Thus, there is a need to establish animal models for specifically studying schizophrenia-related deficits in attentional modulations of PPI.

The neurodevelopmental hypothesis of schizophrenia emphasizes the detrimental influences of certain early-life factors upon brain maturation in eliciting schizophrenic symptoms during adulthood (Buuse et al. 2003). Isolation rearing is one of the widely used animal models for inducing neurodevelopmental impairments of various cognitions/behaviors, including impaired PPI (Geyer et al. 2001; Weiss et al. 2000) and attentional modulations of PPI ( $\mathrm{Li}$ et al.
2009), augmented locomotion (Weiss et al. 2000), impaired learning and memory ( $\mathrm{Li}$ et al. 2007), and declined novel object recognition and attentional set shifting (McLean et al. 2010). All of these behavioral deficits are called "isolation syndromes," which are related to disturbances of some neurotransmitter systems, including hypofunctions of both the $\mathrm{N}$ methyl-D-aspartate receptor (NMDAR) and the metabotropic glutamate receptor 5 (mGluR5) during the maturation process (Arndt et al. 2015).

Moreover, the glutamate hypothesis of schizophrenia emphasizes that non-competitive NMDAR antagonists, such as MK-801, can induce schizophrenia-like symptoms in healthy humans (Geyer et al. 2001). The dysfunction of NMDARs is also associated with some deficits in individuals' development (for a review, see Lim et al. 2012a). For example, NMDAR mediates glutamatergic transmissions that are associated with brain growth and neural plasticity (Komuro and Rakic 1993; Wilson et al. 1998), and blockade of NMDAR in rats using MK-801 during early postnatal days (PND 0-14) causes apoptotic neurodegeneration in a wide range of developing brain regions (Ikonomidou et al. 1999), including the amygdala, hippocampus (Beninger et al. 2002; Manning et al. 2011), and cerebellum (Jantas and Lason 2009; Kanungo et al. 2009). This accelerated programmed cell death following the early MK-801 treatment may also be associated with deficiency of neurotrophic signaling. Specifically, the brain-derived neurotrophic factor (BDNF) and the glial cell line-derived neurotrophic factor (GDNF) promote both neuronal growth and survival in the process of brain development and maturation (Huang and Reichardt 2003; Kang and Schuman 1995; Kaplan and Miller 2000; Luz et al. 2016). Neonatal challenge with MK-801 in rats results in a loss of neurotrophic mRNAs encoding BDNF and GDNF, parallel to a disruption of the ERK1/2-CREB signaling pathway (Hansen et al. 2004). It has been confirmed that NMDARs and related mGluR5 are involved in higher-order cognitive process, such as attention (Amitai et al. 2007; Auclair et al. 2009; Ayala et al. 2009; Semenova and Markou 2007) and learning/memory (Ayala et al. 2009; Fowler et al. 2013; Jia et al. 1998; Palmer et al. 1997; Zou et al. 2007). Phencyclidine (PCP) is another noncompetitive NMDAR antagonist with less selectivity than MK-801. It has been reported that in rats, neonatal PCP treatment exacerbates attentional deficits in the five-choice serial reaction time task (5-CSRTT; Le Pen et al. 2003) and impairs attention shifting (Broberg et al. 2008, 2009) during adulthood. Up to this date, whether early exposure to MK-801 affects attention during adulthood is not clear.

Thus, NMDAR model is a combination of neurodevelopmental and glutamate hypothesis of schizophrenia. It is of interest and importance to investigate whether the early-life MK-801 administration causes specific deficits in attentional modulation of PPI. Comparing the effects of isolation rearing, this study aimed to examine the effects of 
neonatal exposure to MK-801 on the following four measures in adult rats: (1) baseline startle; (2) baseline PPI; (3) modulation of PPI by fear conditioning of the prepulse; and (4) modulation of PPI by perceived spatial separation between the conditioned prepulse and a noise masker. Also, the effects of clozapine on these four measures were examined.

\section{Materials and methods}

\section{Animals and drugs}

Fifty-four Sprague-Dawley pups (20-30 g) along with their lactating mothers were purchased from the Vital-River Experimental Animals Technology Ltd., Beijing, China. From postnatal days (PND) 7 to 10, all the rat pups were intraperitoneally (i.p.) injected with either MK-801 (0.2 mg/ $\mathrm{kg}$, dissolved in the acetic acid saline vehicle; Sigma-Aldrich) or the vehicle (acetic acid saline solution, $1 \mathrm{ml} / \mathrm{kg}$ ) between 0800 and 1000 hours each day. The pups remained in the litter along with their lactating mothers until weaning on PND 21.

After weaning, each of the rats was randomly assigned to either the social rearing group or the isolation rearing (for 8 weeks) group. For isolation-reared rats with saline injection (SAL-IR), each individual was housed in a single transparent plastic cage $(48 \times 30 \times 18 \mathrm{~cm})$. For socially reared rats with either saline injection (SAL-SR) or MK-801 injection (MK$\mathrm{SR}$ ), three individuals were housed in a cage with the same dimensions.

\section{Stimuli and apparatus}

The rat's whole-body startle reflex was induced by an intense 10 -ms broadband noise burst (0-10 kHz, 100-dB SPL) delivered by a loudspeaker above the rat's head. The prepulse stimulus, which started $100 \mathrm{~ms}$ before the onset of startling noise, was a 50-ms three-harmonic tone complex with either lowfrequency components $(1.3,2.6$, and $3.9 \mathrm{kHz}, 60-\mathrm{dB}$ SPL) or high-frequency components $(2.3,4.6$, and $6.9 \mathrm{kHz}, 60-\mathrm{dB}$ SPL). Note that Sprague-Dawley albino rats have a range of hearing from $250 \mathrm{~Hz}$ to $80 \mathrm{kHz}$, with the most sensitivity to tones around $8 \mathrm{kHz}$ (Kelly and Masterton 1977). The frequency components of the prepulse stimuli used in this study were within the hearing range of rats. The prepulse was delivered by each of the two spatially separated loudspeakers, which were placed horizontally in the frontal field with a $100^{\circ}$ separation angle and $52 \mathrm{~cm}$ away from the rat's head position. Sound stimuli were digitally generated by Adobe Audition software and converted by a custom-developed sound delivery system (National Key Laboratory on Machine Perception, Peking University). Calibration of sound intensity was conducted with a Larson Davis Audiometer Calibration and
Electro-acoustic Testing System (AUDit \& System 824, Larson Davis, Depew, NY, USA).

\section{Testing procedures}

The rat was placed in a restraining cage whose dimensions matched the size of the rat body so that the rat could not reorient its head and body positions on PND 77-79. During the adaptation procedure (Fig. 1), the rat was exposed to the background broadband noise which was continuously presented by each of the two horizontal loudspeakers for $30 \mathrm{~min}$ and became adapted to the cage and testing chamber.

Phase I of the testing procedure started on PND 80 (the day before conditioning, BC; Fig. 1). First, the rat received ten presentations of the startling noise without the prepulse presentation on the broadband noise background for $5 \mathrm{~min}$. Then, four testing blocks were introduced. In each of the testing blocks, five trials contained the startling stimulus alone, five trials contained a low-frequency prepulse preceding the startling stimulus, and five trials contained a high-frequency prepulse preceding the startling stimulus. The inter-stimulus onset interval between a prepulse and the startling stimulus was $100 \mathrm{~ms}$. The three types of trials in a testing block were presented in a random order.

A prepulse (with either higher- or lower-frequency components) was presented from each of the two horizontal loudspeakers with the inter-loudspeaker onset delay being either $+1 \mathrm{~ms}$ (left leading) in two testing blocks or $-1 \mathrm{~ms}$ (right leading) in the other two testing blocks. Thus, due to the precedence effect (Litovsky et al. 1999), a single fused prepulse image was perceived at the left loudspeaker in two testing blocks and at the right loudspeaker in the other two testing blocks. In addition, a background broadband noise was continuously delivered from each of the two horizontal loudspeakers as the masker with the inter-masker onset delay between the two loudspeakers being either $+1 \mathrm{~ms}$ (left leading) in two testing blocks or $-1 \mathrm{~ms}$ (right leading) in the other two testing blocks. Thus, a single fused masker image was perceived at the left loudspeaker in two testing blocks and at the right loudspeaker in the other two blocks. Consequently, there were four $(2 \times 2)$ combinations of perceived location relations between the prepulse and the masker covered by these four testing blocks: two blocks with perceptual separation (when the prepulse and masker had different leading positions) and two blocks with perceptual co-location (when the prepulse and the masker had the same leading position). Trials in each testing block were presented with the inter-trial interval around $30 \mathrm{~s}$ (varied between 25 and $30 \mathrm{~s}$ ). The four testing blocks were presented in an order of Latin Design for each of the rat groups.

On PND 81, all the rats underwent both the fearconditioning and the conditioning-control manipulations. For a rat, the conditioning stimulus (CS) was one of the 


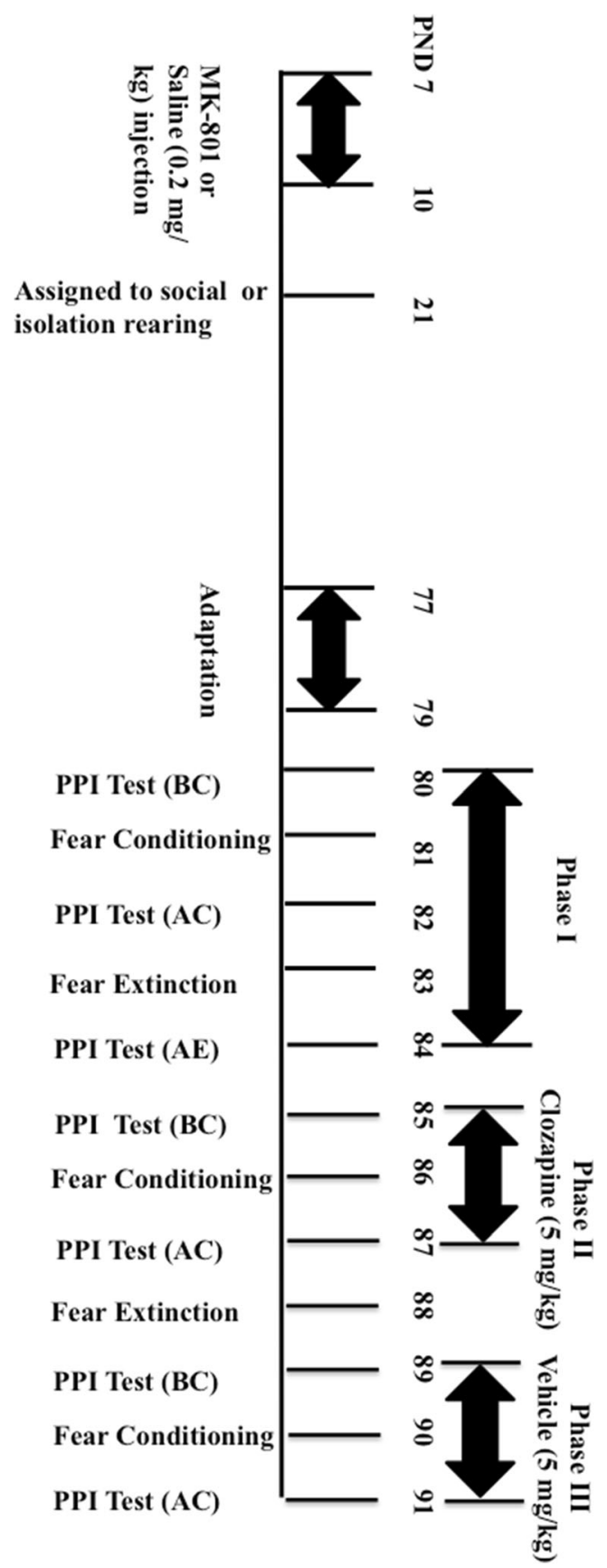

Fig. 1 Experimental timelines for both treatments and testing procedures for the three rat groups. Phase I refers to the testing procedures without clozapine/vehicle treatments. Phase II and Phase III refer to the procedures with clozapine and vehicle treatments, respectively. $B C$ before conditioning, $A C$ after conditioning, $A E$ after extinction

prepulse stimuli (either lower- or higher-frequency prepulse) delivered by each of the two horizontal loudspeakers with a left/right-leading balance, and the unconditioned stimulus (US) was a 6-mA rectangular-pulse footshock with a duration of 3 ms provided by a Grass S-88 stimulator (Grass, Quincy, MA, USA; following Zou et al. 2007). For all of the rat groups, fear conditioning was established by 20 temporally synchronized (paired) combination of the low- or highfrequency prepulse with the footshock (footshock started $3 \mathrm{~ms}$ before the prepulse ending and co-terminated with the prepulse, following Zou et al. 2007). Conditioning-control manipulation was conducted by 20 combinations between the high- or low-frequency prepulse and the footshock with temporally random (unpaired) prepulse-footshock intervals within the time window of $30 \mathrm{~s}$. The order of conducting conditioning and conditioning-control manipulations were balanced across rats.

On PND 82 ( $24 \mathrm{~h}$ after the fear-conditioning/conditioningcontrol manipulations), PPI after conditioning (AC) was measured with the same procedure as on PND 80. On PND 83, all the rats underwent the manipulation of fear extinction, during which the CS was presented every $30 \mathrm{~s}$ (without pairing with the footshock US) for 60 times (three blocks with 20 presentations in each block and a 10-min inter-block interval). On PND 84 ( $24 \mathrm{~h}$ after the extinction manipulation), PPI after extinction (AE) was measured with the same procedure as used on PND 80.

Phase II and Phase III of the testing procedure were conducted from PND 85 to 87 and from PND 89 to 91, respectively. All the rats were intraperitoneally injected with clozapine $(5 \mathrm{mg} / \mathrm{kg})$ in Phase II and with vehicle in Phase III through the three consecutive days in each of the two phases. The following procedures were carried out $30 \mathrm{~min}$ after injection:

On PND 85 and 89, testing before fear conditioning (BC) was conducted with the same procedure as used on PND 80.

On PND 86 and 90, both the fear-conditioning and conditioning-control manipulations were conducted with the same procedure as used on PND 81.

On PND 87 and 91, PPI after conditioning (AC) was measured with the same procedure as used on PND 80.

On PND 88, all the rats underwent the manipulation of fear extinction using the procedures as used on PND 83.

\section{Data analyses}

The value of PPI was calculated with the following generally used formula:

$\operatorname{PPI}(\%)=$ (amplitude to startling noise alone-amplitude to startling noise preceded by prepulse)/(amplitude to startling noise alone) $\times 100 \%$.

Analyses of variance (ANOVAs) were conducted using SPSS 15.0 software. The null hypothesis rejection level was set at 0.05 . 


\section{Results}

\section{Baseline startle}

The upper panel of Fig. 2 illustrates the group mean amplitudes of the startle reflex in the three groups at the $\mathrm{BC}$ procedure stage in each of the three testing phases. Obviously, the baseline startle amplitudes of the SAL-IR and those of the MK-SR groups were larger than those of the SAL-SR group.

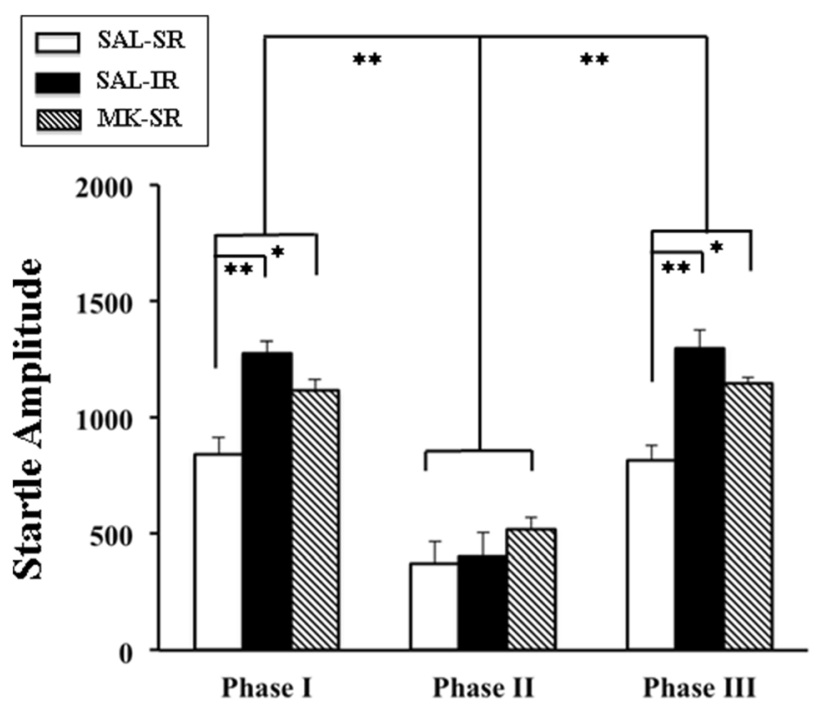

BC Stage across Phases

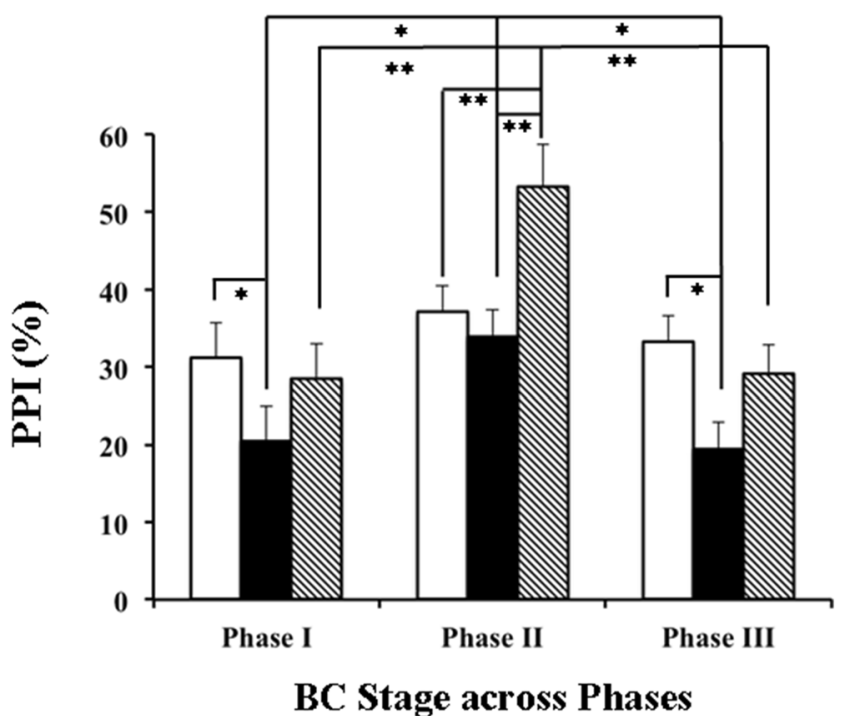

Fig. 2 Upper panel shows the group mean amplitudes of the startling reflex to the startling noise alone in each of the three rat groups before the fear-conditioning/conditioning-control manipulations Phases I, II, and III. The magnitude of the startle reflex was calculated with the device scale unit. Lower panel shows the amplitudes of PPI in each of the three rat groups before the fear-conditioning/conditioning-control manipulations in Phases I, II, and III. PPI values were obtained at the procedure stage $\mathrm{BC}$ under the perceived prepulse-masker co-location condition. ${ }^{*} p<0.05,{ }^{* *} p<0.01$
Clozapine (injected in Phase II) generally reduced baseline startle.

A 3 (phase stage) by 3 (group) mixed repeated-measures ANOVA showed that the main effect of the phase stage was significant $\left(F_{(2,16)}=186.356, p<0.01\right)$, the main effect of group was significant $\left(F_{(2,16)}=16.092, p<0.01\right)$, and the interaction was significant $\left(F_{(4,14)}=3.390, p<0.05\right)$. Post hoc Bonferroni tests showed that (1) in Phase I, baseline startle of the SAL-SR group was significantly lower than that of the SAL-IR group $(p<0.01)$ and that of the MK-SR group $(p<0.05)$; (2) in Phase II (with clozapine injection), there was no group difference (all $p>0.05$ ); and (3) in Phase III, the baseline startle amplitude of the SAL-SR group was significantly lower than that of the SAL-IR group $(p<0.01)$ and that of the MK-SR group $(p<0.05)$. Also, separate withinsubject repeated-measures ANOVAs showed that for each group across the testing phases, baseline startle was significantly reduced in Phase II (SAL-SR: $F_{(2,16)}=26.959$, $p<0.01$; SAL-IR: $F_{(2,16)}=41.981, p<0.01$; MK-SR: $\left.F_{(2,16)}=52.336, p<0.01\right)$.

\section{Baseline PPI}

Under the prepulse/masker co-location condition, baseline PPI was compared between groups at procedure stage BC across the testing phases. The bottom panel of Fig. 2 shows that in Phase I, the baseline PPI of the SAL-IR group was lower than those of the SAL-SR and MK-SR groups. After clozapine was applied in Phase II, baseline PPI was increased in both the SAL-IR and the MK-SR groups. These PPI enhancements did not occur in Phase III (with vehicle injection).

A 3 (phase) by 3 (group) mixed repeated-measures ANOVA showed that the main effect of phase stage was significant $\left(F_{(2,16)}=10.178, p<0.01\right)$, the main effect of group was significant $\left(F_{(2,16)}=8.211, p<0.01\right)$, and the interaction was significant $\left(F_{(4,14)}=3.444, p<0.05\right)$. Post hoc Bonferroni tests showed that (1) in Phase I, the baseline PPI of the SALIR group, but not that of the MK-SR group, was significantly lower than that of the SAL-SR group $(p<0.05)$; (2) in Phase II, the baseline PPI of the MK-SR group was significantly larger than those of the SAL-SR $(p<0.01)$ and SAL-IR $(p<0.01)$ groups; and (3) in Phase III, the baseline PPI of the SAL-IR group, but not that of the MK-SR group, was significantly lower than that of the SAL-SR group $(p<0.05)$.

Moreover, within-subject repeated-measures ANOVA for each group showed that the effect of phase stage was significant in both the SAL-IR $\left(F_{(2,16)}=3.332, p<0.05\right)$ and MKSR $\left(F_{(2,16)}=15.367, p<0.01\right)$ groups, but not in the SAL-SR group $\left(F_{(2,16)}=0.039, p>0.05\right)$. For these two neonatally disrupted groups, post hoc Bonferroni tests indicated that the baseline PPI value was significantly larger in Phase II (with clozapine injection) than both that in Phase I (SAL-IR, 
$p<0.05$; MK-SR, $p<0.01)$ and that in phase III (SAL-IR, $p<0.05$; MK-SR, $p<0.01)$.

\section{Attentional modulations of PPI in Phase I}

Figure 3 shows both the effect of fear conditioning of a prepulse on PPI and the effect of perceptual separation either between the noise masker and the conditioned prepulse (CS+, left panels) or between the noise masker and the conditioningcontrol prepulse (CS-, right panels) on PPI. Before fear conditioning (BC) in each group, since the mean PPI magnitude induced by the low-frequency prepulse was not significantly different from that induced by the high-frequency prepulse (all $p>0.05$, paired $t$ tests), the PPI values induced by the two prepulse types were combined.

\section{SAL-SR group}

For the SAL-SR group, as shown by the top panels of Fig. 3, after a prepulse was fear conditioned, PPI induced by this CS+ , but not that by the CS-, was enhanced. Also, relative to the perceptual co-location condition, perceived spatial separation between the noise masker and the $\mathrm{CS}+$, but not the $\mathrm{CS}-$, further enhanced PPI. Finally, the extinction manipulation eliminated both the fear conditioning effect and the perceptual separation effect.
Fig. 3 Magnitudes of PPI induced by the conditioned prepulse (CS+, left panel) and the conditioning-controlled prepulse (CS-, right panel) in each of the three rat groups at different procedure stages in Phase I. White bars represent the condition when the prepulse was perceptually co-located with the noise masker, while diagonal bars represent the condition when the prepulse was perceptually separated from the noise masker. $C S+$ the prepulse was fear-conditioned, $C S-$ the prepulse was conditioning-controlled, $S A L-S R$ socially reared rats with neonatal saline injection, $S A L-I R$ isolation-reared rats with neonatal saline injection, $M K-S R$ socially reared rats with neonatal MK-801 injection. ${ }^{*} p<0.05$, $* * p<0.01$

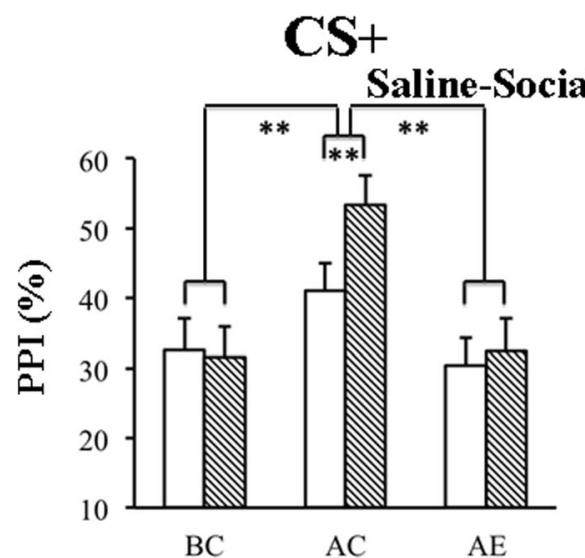

Saline-Isolation Rearing

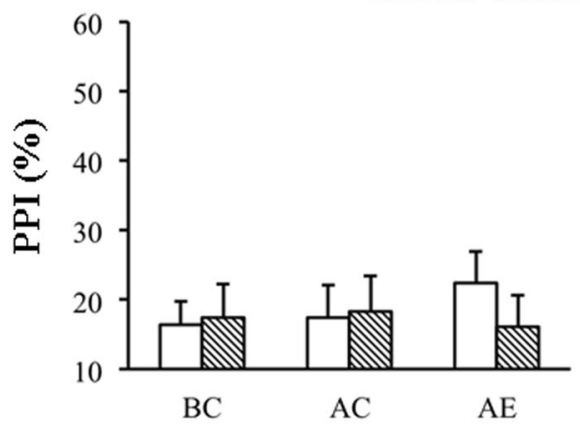

60
50
40
30
20
10
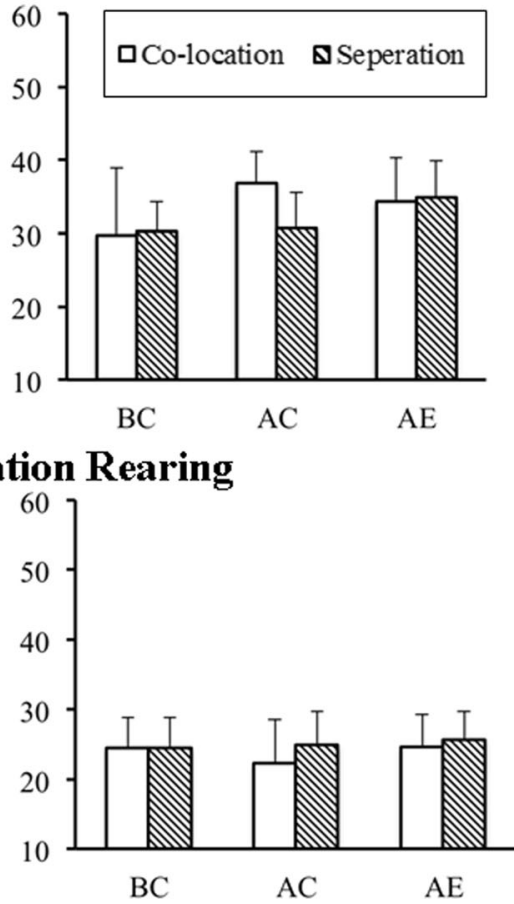

MK-801-Socially Rearing
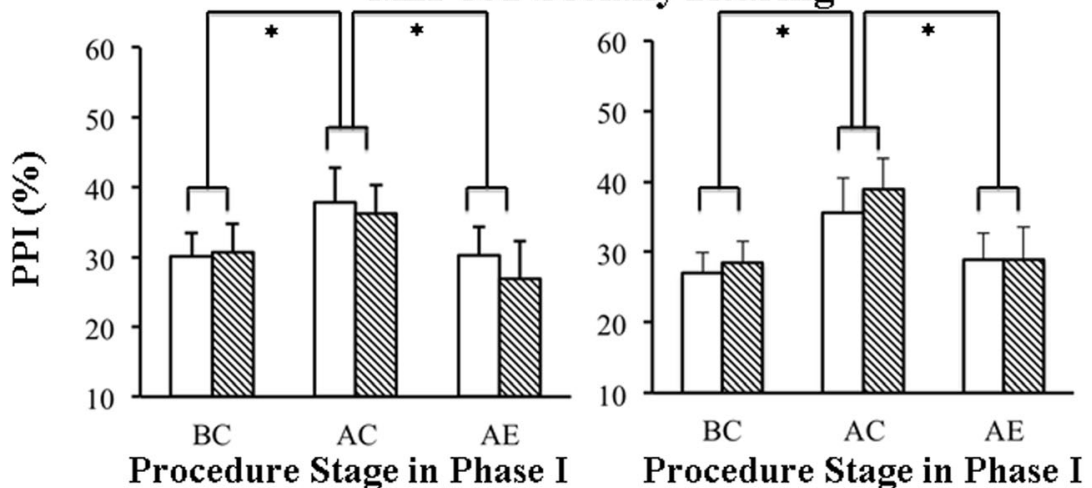
For PPI induced by the CS+, a 3 (procedure stages: BC, $\mathrm{AC}$, and $\mathrm{AE}$ ) by 2 (separation type: separation and co-location) within-subject repeated-measures ANOVA showed that the main effect of procedure stage was significant $\left(F_{(2,16)}=12.450, p<0.01\right)$, the main effect of separation type was significant $\left(F_{(1,17)}=5.579, p<0.05\right)$, and the interaction was significant $\left(F_{(2,16)}=6.074, p<0.05\right)$. Post hoc Bonferroni tests showed that (1) at procedure stage BC, PPI was not significantly affected by separation type ( $p>0.05)$; (2) at procedure stage AC, PPI was significantly enhanced $(p<0.05)$, and the effect of separation type became significant $\left(t_{(17)}=4.432, p<0.01\right)$; and (3) at procedure stage AE, the PPI levels under all the conditions reduced to the ones at procedure stage $\mathrm{BC}(p>0.05)$, including the effect of perceptual separation becoming not significant $(p>0.05)$. For PPI induced by the CS-, another $3 \times 2$ within-subject repeatedmeasures ANOVA showed that neither each of the main effect (procedure stage: $F_{(2,16)}=0.380, p>0.05$; separation type: $\left.F_{(1,17)}=0.531, p>0.05\right)$ nor the interaction was significant $\left(F_{(2,16)}=1.101, p>0.05\right)$.

\section{SAL-IR group}

For PPI induced by either the CS+ or the CS- in the SAL-IR group (Fig. 3, middle panels), neither the fear conditioning effect nor the perceptual separation effect on PPI was present. The $3 \times 2$ within-subject repeated-measures ANOVAs showed that neither the main effects nor the interaction was significant on PPI induced by either the $\mathrm{CS}+$ (procedure stage: $F_{(2,16)}=0.138, p>0.05$; separation type: $F_{(1,17)}=0.243$, $p>0.05$; interaction: $\left.F_{(2,16)}=0.486, p>0.05\right)$ or the CS(procedure stage: $F_{(2,16)}=0.188, p>0.05$; separation type: $F_{(1,17)}=0.202, p>0.05$; interaction: $\left.F_{(2,16)}=0.176, p>0.05\right)$.

\section{MK-SR group}

For the MK-SR group (Fig. 3, bottom panels), fear conditioning enhanced both PPI induced by the CS+ and PPI induced by the CS-, without exhibiting the prepulse feature specificity.

For PPI induced by the CS+, a $3 \times 2$ within-subject repeated-measures ANOVA showed that the main effect of procedure stage was significant $\left(F_{(2,16)}=7.190, p<0.05\right)$, but both the main effect of separation type $\left(F_{(1,17)}=0.515, p>0.05\right)$ and the interaction $\left(F_{(2,16)}=0.346, p>0.05\right)$ were not significant. Post hoc Bonferroni tests showed that (1) at procedure stage AC, PPI was significantly enhanced $(p<0.05)$; (2) at procedure stage $\mathrm{AE}$, the PPI levels reduced to the ones at procedure stage $\mathrm{BC}(p>0.05)$; and (3) the perceptual separation effect was not significant at each of the procedure stages $(p>0.05)$.

For PPI induced by the CS-, another $3 \times 2$ within-subject repeated-measures ANOVA showed that the main effect of procedure stage was significant $\left(F_{(2,16)}=6.102, p<0.05\right)$, but both the main effect of separation type $\left(F_{(1,17)}=1.415\right.$, $p>0.05)$ and the interaction $\left(F_{(2,16)}=0.220, p>0.05\right)$ were not significant. Post hoc Bonferroni tests showed that (1) at procedure stage AC, PPI was significantly enhanced $(p<0.05)$; (2) at procedure stage $\mathrm{AE}$, all the PPI levels reduced to the ones at procedure stage $\mathrm{BC}(p>0.05)$; and (3) the perceptual separation effect was not significant at each of the procedure stages $(p>0.05)$.

\section{Attentional modulations of PPI in Phase II with clozapine injection}

\section{SAL-SR group}

For the SAL-SR group (Fig. 4, top panels), clozapine did not abolish the fear conditioning-induced PPI enhancement that

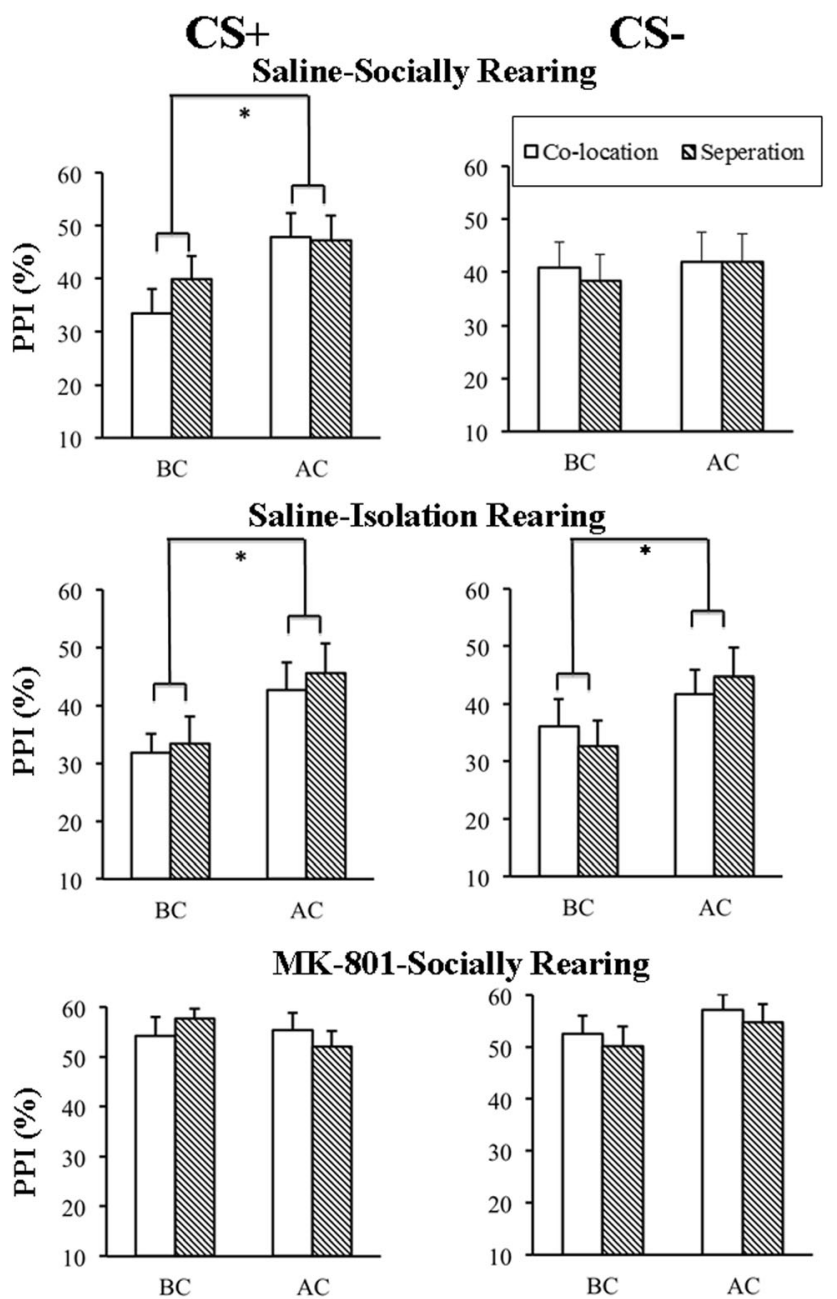

Procedure Stage in Phase II Procedure Stage in Phase II

Fig. 4 Magnitudes of PPI induced by the conditioned prepulse (CS+, left panel) and conditioning-controlled prepulse (CS-, right panel) in each of the three rat groups at different procedure stages in Phase II (after clozapine treatment). $* p<0.05, * * p<0.01$ 
exhibited the prepulse specificity. However, the perceptual separation-induced PPI enhancement disappeared.

For PPI induced by the CS+, a 2 (procedure stages: $\mathrm{BC}$ and AC) by 2 (separation type) within-subject repeated-measures ANOVA showed that the main effect of procedure stage was significant $\left(F_{(1,17)}=5.787, p<0.05\right)$, but neither the main effect of separation type $\left(F_{(1,17)}=0.873, p>0.05\right)$ nor the interaction was significant $\left(F_{(1,17)}=1.247, p>0.05\right)$.

For PPI induced by the CS-, neither the two main effects (procedure stage: $F_{(1,17)}=0.732, p>0.05$; separation type: $\left.F_{(1,17)}=0.119, p>0.05\right)$ nor the interaction $\left(F_{(1,17)}=0.236\right.$, $p>0.05$ ) was significant.

\section{SAL-IR group}

For the SAL-IR group (Fig. 4, middle panels), clozapine restored the fear conditioning-induced PPI enhancement when the prepulse was either the CS+ or CS-, without showing the prepulse feature specificity. Moreover, clozapine had no restoring effects on the modulation of PPI by perceptual separation.

For PPI induced by the CS+, a $2 \times 2$ within-subject repeated-measures ANOVA showed that the main effect of procedure stage was significant $\left(F_{(1,17)}=7.654, p<0.05\right)$, but neither the main effect of separation type $\left(F_{(1,17)}=0.693\right.$, $p>0.05)$ nor the interaction $\left(F_{(1,17)}=0.039, p>0.05\right)$ was significant. For PPI induced by the CS-, another $2 \times 2$ within-subject repeated-measures ANOVA showed that the main effect of procedure stage was significant $\left(F_{(1,17)}=4.450, p<0.05\right)$, but neither the main effect of separation type $\left(F_{(1,17)}=0.006, p>0.05\right)$ nor the interaction $\left(F_{(1,17)}=1.227, p>0.05\right)$ was significant.

\section{MK-SR group}

For the MK-SR group (Fig. 4, bottom panels), neither the fear conditioning effect nor the perceptual separation effect on PPI exhibited in Phase II. The $2 \times 2$ within-subject repeated-measures ANOVAs showed that neither the two main effects nor the interaction was significant for either PPI induced by the CS+ (procedure stage: $F_{(1,17)}=0.490, p>0.05$; separation type: $F_{(1,17)}=0.001, p>0.05$; interaction: $F_{(1,17)}=1.472$, $p>0.05$ ) or PPI induced by the CS- (procedure stage: $F_{(1,17)}=1.500, p>0.05$; separation type: $F_{(1,17)}=1.424$, $p>0.05$; interaction: $\left.F_{(1,17)}=0.002, p>0.05\right)$.

\section{Attentional modulations of PPI in Phase III with vehicle injection}

\section{SAL-SR group}

For the SAL-SR group (Fig. 5, top panels), similar to the results in Phase I, PPI induced by the $\mathrm{CS}^{+}$, but not that by

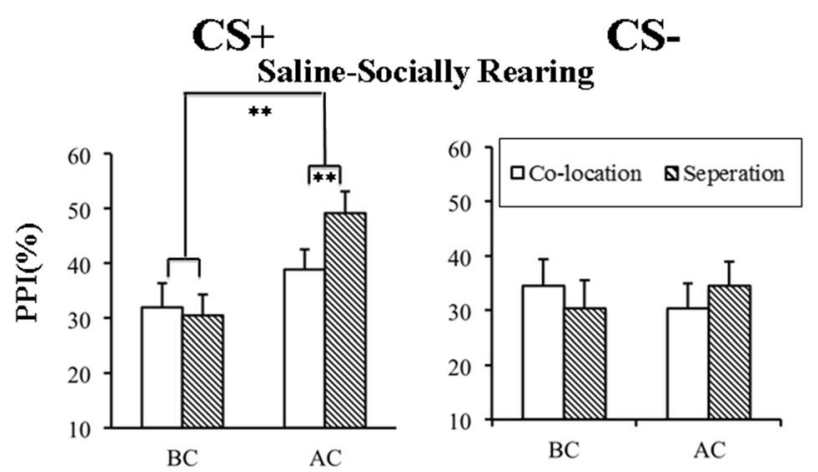

Saline-Isolation Rearing
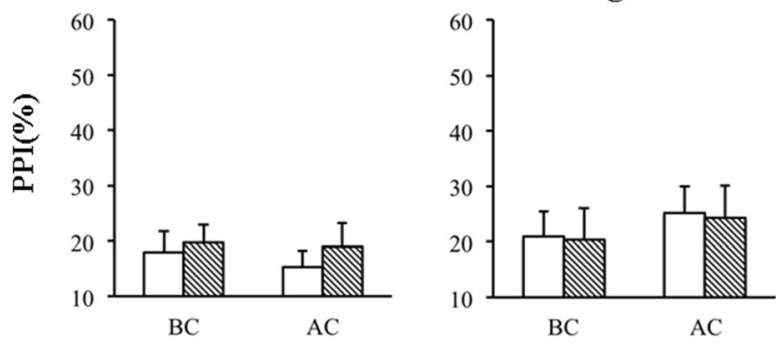

MK-801-Socially Rearing
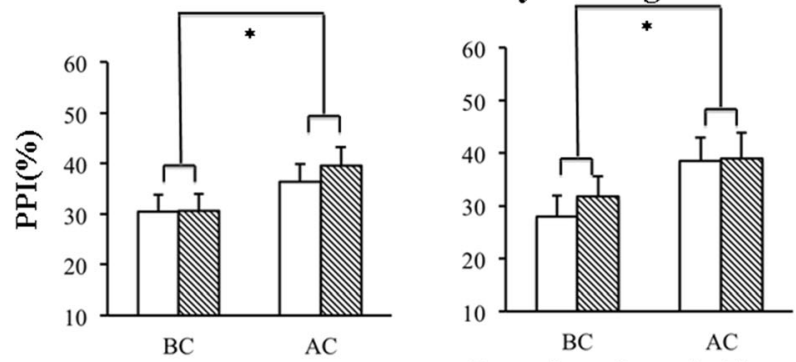

Procedure Stage in Phase III Procedure Stage in Phase III

Fig. 5 Amplitudes of PPI induced by the conditioned prepulse (CS+, left panel) and conditioning-controlled prepulse (CS-, right panel) in each of the three rat groups at different procedure stages in Phase III (after vehicle treatment). ${ }^{*} p<0.05, * * p<0.01$

the CS-, was enhanced after fear conditioning. Also, perceived spatial separation between the masker and the CS+, but not that between the masker and the CS-, further enhanced PPI.

For PPI induced by the CS+, a $2 \times 2$ within-subject repeated-measures ANOVA showed that both the main effect of procedure stage $\left(F_{(1,17)}=12.234, p<0.01\right)$ and the main effect of separation type were significant $\left(F_{(1,17)}=6.250, p<0.05\right)$, and the interaction was significant $\left(F_{(1,17)}=10.603, p<0.01\right)$. Post hoc Bonferroni tests confirmed that (1) at procedure stage BC, PPI was not affected by separation type $(p>0.05)$ and $(2)$ at procedure stage AC, PPI was significantly enhanced $(p<0.05)$, and the effect of separation type became significant $\left(t_{(17)}=5.240, p<0.01\right)$.

For PPI induced by the CS-, another $2 \times 2$ within-subject repeated-measures ANOVA showed that neither the two main effects (procedure stage: $F_{(1,17)}=0.000, p>0.05$; separation type: $\left.F_{(1,17)}=0.000, p>0.05\right)$ nor the interaction $\left(F_{(1,17)}=1.313, p>0.05\right)$ was significant. 


\section{SAL-IR group}

For the SAL-IR group (Fig. 5, middle panels), neither the fear conditioning nor the perceptual spatial separation enhanced PPI. A $2 \times 2$ within-subject repeated-measures ANOVA showed that neither the main effects of procedure stage and separation type nor the interaction was significant for either PPI induced by the CS+ (left panel; procedure stage: $F_{(1,17)}=0.280, p>0.05$; separation type: $F_{(1,17)}=1.588$, $p>0.05$; interaction: $\left.F_{(1,17)}=0.189, p>0.05\right)$ or PPI induced by the CS- (right panel; procedure stage: $F_{(1,17)}=0.072$, $p>0.05$; separation type: $F_{(1,17)}=0.142, p>0.05$; interaction: $\left.F_{(1,17)}=0.101, p>0.05\right)$.

\section{MK-SR group}

For the MK-SR group (Fig. 5, bottom panels), fear conditioning a prepulse enhanced PPI induced by either the CS+ or CS -. No perceptual separation effect on PPI was exhibited.

For PPI induced by the CS+, a $2 \times 2$ within-subject repeated-measures ANOVA showed that the main effect of procedure stage was significant $\left(F_{(1,17)}=4.608, p<0.05\right)$, but the main effect of separation type $\left(F_{(1,17)}=1.214, p>0.05\right)$ and the interaction $\left(F_{(1,17)}=0.876, p>0.05\right)$ were not significant. Post hoc Bonferroni tests showed that after fear conditioning, PPI was significantly increased $(p<0.05)$, but there was no significant perceptual separation effect $(p>0.05)$.

For PPI induced by the CS-, another $2 \times 2$ within-subject repeated-measures ANOVA showed that the main effect of procedure stage was significant $\left(F_{(1,17)}=5.265, p<0.05\right)$, but the main effect of separation type $\left(F_{(1,17)}=1.764\right.$, $p>0.05)$ and the interaction $\left(F_{(1,17)}=1.475, p>0.05\right)$ were not significant. Post hoc Bonferroni tests showed that after fear conditioning, the PPI value was significantly increased $(p<0.05)$, but there was no significant perceptual separation effect $(p>0.05)$.

\section{Discussions}

Although the neural circuit mediating PPI resides in the brainstem (Li and Frost 2000), PPI can be top-down modulated by higher-order cognitive process (for a review, see Li et al. 2009). In this study, the three rat groups demonstrated different responding patterns not only in baseline startle and baseline PPI but also in fear-conditioning and perceptualseparation modulations of PPI.

\section{Baseline startle and baseline PPI}

The results of this study showed that adult rats with either isolation rearing or neonatal exposure to MK-801 exhibited larger startle amplitudes than normally reared rats. Thus, the two neonatal disruptions (isolation rearing and neonatal exposure to MK-801) generally cause adult rats more stress than socially reared rats and consequently enhance startle (Du et al. 2009, 2010).

Moreover, rats with isolation rearing, but not rats with neonatal MK-801 exposure, exhibited a significant reduction of baseline PPI, consistent with previous reports (Du et al. 2009, 2010). It should be noted that the effects of neonatal exposure to MK-801 on baseline PPI may be both strain- (Lim et al. 2012a, b; Uehara et al. 2009, 2010, 2014) and sex-dependent (Lim et al. 2012a, b; Nozari et al. 2015). The absence of effects of the neonatal exposure to MK-801 on baseline PPI may specifically occur in Sprague-Dawley male rats.

\section{Modulation of PPI by fear conditioning of the prepulse}

The main purpose of this study was to examine whether neonatal exposure to MK-801 affects attentional modulations of PPI. The results showed that socially reared rats, either with or without neonatal exposure to MK-801, exhibited the fear conditioning-induced PPI enhancement. Moreover, the prepulse feature specificity of this PPI enhancement was maintained well only in normally reared rats and disappeared in neonatally MK-801-treated rats. Thus, although neonatal exposure to MK-801 does not abolish the fear conditioninginduced PPI enhancement, it affects the processing of prepulse features. Also, consistent with previous reports (Du et al. 2009, 2010), in this study, rats with isolation rearing did not exhibit the fear conditioning-induced PPI enhancement.

Based on previous studies, mGluR5 is involved in fear conditioning-induced PPI modulation because administration of MPEP (an mGluR5 antagonist) abolishes this type of modulation (Lei et al. 2014; Zou et al. 2007). On the other hand, Du et al. (2011) have discovered that blocking the lateral nucleus of the amygdala abolishes fear conditioning-induced PPI enhancement in normally reared rats. Moreover, some previous studies have shown that isolation rearing not only reduces the functions of both NMDARs and mGluR5 during maturation (Arndt et al. 2015) but also impairs cellular signaling pathways of neurons in the basolateral amygdala (Karkhanis et al. 2015) and particularly decreases the expression of the immediate-early gene Egr-1 that encodes synaptic plasticityrelated signaling in the amygdala (Okada et al. 2014). Thus, in the future, it is important to further examine whether the isolation rearing-induced impairment of neural processes of the amygdala is the major cause of the absence of the fear conditioning-induced PPI enhancement.

On the other hand, according to the results of this study, early exposure to MK-801 restores the fear conditioninginduced PPI enhancement, but causes loss of the prepulse feature specificity. Previous studies have shown that although the lateral amygdala (LA) is critical to the conditioninginduced PPI enhancement of PPI (Du et al. 2011), neonatal 
exposure to MK-801 does not substantially impair the functions of the amygdala (Uehara et al. 2014).

Why does neonatal MK-801 intervention specifically impair frequency discrimination after fear conditioning? It has been known that most auditory neurons in the amygdala do not demonstrate selective sensitivity to sound frequencies (Bordi and LeDoux 1992), suggesting that the amygdala itself contributes little to the prepulse feature specificity in the fear conditioning-induced PPI enhancement. However, LA receives axonal projections from not only the auditory thalamus (e.g., media geniculate nucleus) but also the auditory association cortex (AAC/TE3). The LA itself is not sufficient to discriminate the sound frequencies before fear conditioning (Du et al. 2012), but neurons in the primary auditory cortex (TE1) have selective responses to tones with various frequencies from 1 to $40 \mathrm{kHz}$ (Kelly and Sally 1988) and play a role in modulating amygdala activities via the AAC (Romanski and LeDoux 1993). Thus, normally, fear conditioning a sound enhances the functional connectivity between the LA and TE1 via AAC (TE3), leading to the conditioning-enhanced responses of the LA to the sound with the sound feature specificity (Du et al. 2012), which may be mediated by $\mathrm{GABA}_{\mathrm{B}}$ receptors (Huang et al. 2005).

Moreover, the medial prefrontal cortex (mPFC) receives inputs from the $\mathrm{AAC}$ and modulates principal neurons in the LA (for a discussion, see Huang et al. 2005). Pharmacological reductions in mPFC GABA transmission impair discriminative aversive conditioning (Piantadosi and Floresco 2014). In addition, the dysfunction of GABA transmissions in the amygdalo-hippocampal system leads to fear generalization (Bergado-Acosta et al. 2008). It has been found that neonatal exposure to MK-801 significantly reduces the number of parvalbumin-positive GABAergic neurons in the mPFC (Uehara et al. 2012; Abekawa et al. 2007; Li et al. 2015) and changes the ratio of vesicular glutamate and GABA transporters in the hippocampus during adulthood ( $\mathrm{Li}$ et al. 2015). In people with schizophrenia, dysfunctional emotional processing is associated with abnormal GABAergic activity in the dorsal medial prefrontal cortex (Taylor et al. 2014) and the visual cortex (Tso et al. 2015). Thus, another important issue for future investigation is whether impaired GABAergic transmissions in the mPFC and/or hippocampus following neonatal exposure to MK-801 cause the loss of prepulse feature specificity in fear conditioning-induced PPI enhancement.

In people with schizophrenia, processing of emotional information is impaired (Swart et al. 2013), and the impairment involves an impaired regulation of GABA transmission in the circuits including the prefrontal cortex (Piantadosi and Floresco 2014). Thus, the neonatal MK- 801 animal model is useful for further investigating the relationship between impaired attentional modulations of PPI, impaired sound feature processing, and impaired GABAergic transmissions.

\section{Modulation of PPI by perceived spatial separation}

In agreement with previous studies (Du et al. 2009, 2010, 2011), the results of this study showed that in normally reared rats, perceived spatial separation between the noise masker and the conditioned prepulse (CS+), but not the prepulse used for conditioning control ( $\mathrm{CS}-$ ), further enhanced PPI. In humans, this perceived spatial separation of the target and a masker facilitates the listener's selective attention to target signals and improves recognition of the target (Freyman et al. 1999; Li et al. 2004; Zheng et al. 2015). Interestingly, in both rats and humans, the perceptual separation-induced behavioral improvements are normally based on the PPC (Du et al. 2011; Zheng et al. 2015), which also has axonal connections with the prefrontal cortex (Reep et al. 1994) and plays a role in guiding actions toward spatial goals (Andersen and Cui 2009).

The results of this study also showed that the perceptual separation-induced PPI enhancement did not occur in both isolation-reared rats and neonatally MK-801-treated rats, indicating that the perceptual separation-induced PPI enhancement is more vulnerable to neonatal interruptions than fear conditioning-induced PPI enhancement.

For isolation-reared rats, the failure of perceptual separation in enhancing PPI may be related to their impaired attentional shift (McLean et al. 2010) or impaired spatial attention to the conditioned prepulse (Du et al. 2009). As mentioned above, isolation rearing leads to a broad range of structural and functional abnormalities (including dopamine, glutamate, and serotonin; Leng et al. 2004; Melendez et al. 2004), which may be associated with the deficits in the attentional modulations of PPI.

The ability to perceptually integrate the prepulse stimuli from two separated spatial locations requires calculating the correlation (similarity) of the acoustic features of the leading and lagging sounds ( $\mathrm{Li}$ et al. 2009). In this study, since neonatally MK-801-treated rats showed deficits in discriminating prepulse frequency during fear conditioning, the feature processing deficits may affect the perceptual integration of the prepulse signals, leading to the lack of separation-induced PPI enhancement in rats with neonatal MK-801 exposure.

Moreover, neonatal MK-801 exposure causes some neurotoxicity effects in the hypothalamus, amygdala (Otoya et al. 1997), hippocampus (Gilland et al. 1997; Otoya et al. 1997), and posterior brain regions (Gilland et al. 1997). Some studies have shown that in rats, MK-801 disrupts spatial processing at both the perceptual and cognitive levels, including both failure to locate the target location (Terry et al. 2011) and failure to detect spatial novelty (Usiello et al. 1998). Thus, the lack of separation-induced PPI enhancement in rats with neonatal MK-801 exposure may also be associated with impaired spatial ability. 
People with schizophrenia exhibit impaired selective attention (Dalmaso et al. 2013; Strauss et al. 2011) and recognition of target speech under masking conditions (Zheng et al. 2015). Neonatal MK-801 animal models are useful for improving animal models to investigate the spatial attention deficits of schizophrenia, especially under adverse listening conditions.

\section{Effects of clozapine on attentional modulations of PPI}

In this study, clozapine showed various effects on the four measures (baseline startle, baseline PPI, fear conditioninginduced PPI enhancement, and perceptual separationinduced PPI enhancement) in different rat groups.

First of all, since clozapine generally decreases the baseline startle amplitude (this study; Frogley et al. 2012), it has a sedative effect.

In addition, according to the results of this study, clozapine applied during adulthood enhances baseline PPI in both isolation-reared rats and neonatally MK-801-treated rats, but not in normally reared rats, indicating a sensitivity of baseline PPI to clozapine in neonatally disrupted rats (Le Pen and Moreau 2002).

Moreover, the results of this study showed that clozapine had various effects on the fear conditioning-mediated modulation of PPI in different rat groups: Clozapine did not affect the conditioning-induced PPI enhancement in normally reared rats, but abolished this PPI enhancement in neonatally MK801-treated rats. More interestingly, clozapine restored the fear conditioning-induced PPI enhancement in isolationreared rats with loss of the prepulse feature specificity. It has been well known that the affinities of clozapine at various receptors play an important role in ameliorating schizophrenia-related neurochemical abnormalities and cognitive/behavioral deficiencies (Sebban et al. 2002; Spagna et al. 2015). For example, clozapine can reduce isolation rearing-induced deficits in reversal learning in the newstrategy-acquisition phase ( $\mathrm{Li}$ et al. 2007). Since reversal learning largely depends on the function of the mPFC ( $\mathrm{Li}$ and Shao 1998), certain isolation rearing-induced neurotransmission impairments in the MPFC may be partially ameliorated by clozapine. Moreover, clozapine also reduces isolation rearing-induced deficits in PPI (Heidbreder et al. 2001; Le Pen and Moreau 2002; Möller et al. 2011, 2013), object recognition memory (Möller et al. 2013), social interactive behavior (Möller et al. 2011, 2013), and emotional behavior (Koike et al. 2009). Up to this date, it is not clear whether certain isolation rearing-induced neurotransmission impairments in the amygdala can be ameliorated by clozapine. On the other hand, clozapine acts as an antagonist for the $\mathrm{GABA}_{\mathrm{A}}$ receptor (for a review, see O'Connor and O'Shea 2015). It has been reported that clozapine both decreases extracellular GABA level within the PFC (Bourdelais and Deutch 1994) and reduces the density of $\mathrm{GABA}_{\mathrm{A}}$ receptors in the hippocampus (Farnbach-Pralong et al. 1998). Thus, the loss of prepulse feature in the emotional PPI enhancement after clozapine treatment in isolation-reared rats may be associated with the impaired GABA transmission in the PFC and/or hippocampus. These different effects of clozapine on the fear conditioning-induced PPI modulation between isolationreared rats, neonatally MK-801-treated rats, and normally reared rats further support the view that isolation rearing and neonatal exposure to MK-801 cause different neural impairments.

Finally, the results of this study showed that clozapine impaired normally reared rats' spatial attention to the conditioned prepulse because it abolished the perceptual separationinduced PPI enhancement. Also, clozapine did not restore the perceptual separation-induced PPI enhancement in either isolation-reared rats or neonatally MK-801-treated rats. The results of this study are in agreement with previous studies showing that clozapine does not restore impairment of spatial memory in neonatally MK-801-administered rats (Liu et al. 2014). Thus, there is a need to develop new antipsychotics that do not affect spatial processing in animal models.

In people with schizophrenia, clozapine impairs higherorder cognitive processes (Houthoofd et al. 2008) and does not improve spatial memory (Meltzer and McGurk 1999). The specific deficits in perceptual separation-induced PPI enhancement in neonatally MK-801-treated rats will be useful for establishing a new animal model not only for studying the mechanisms underlying schizophrenia but also for examining the efficacy of potential antipsychotics.

\section{Conclusions}

Using the paradigms of attentional modulation of PPI, we compared the effects of isolation rearing and those of neonatal exposure to MK-801 on the following four measures: baseline startle, baseline PPI, enhancement of PPI by fear conditioning of the prepulse, and enhancement of PPI by spatial perceptual separation between the conditioned prepulse and a noise masker. The following findings were obtained.

At the level of baseline startle, both isolation rearing and neonatal MK-801 exposure enhance the startle amplitude.

At the level of baseline PPI, only isolation rearing has an impairing effect.

At the levels of fear-conditioning modulation and spatial attentional modulation of PPI, normally reared rats, with the remarkable prepulse feature specificity, exhibit both the PPI enhancement by fear conditioning and that by perceptual spatial separation. Isolation rearing abolishes these two types of enhancement. Neonatal exposure to MK-801 only abolishes the separation-induced PPI enhancements and reserves fear conditioning-induced PPI enhancement with loss of the prepulse feature specificity. Thus, early-life MK-801 
treatment specifically impairs spatial attention which is associated with failure in discriminating prepulse features, while isolation rearing induces a much wider range of attentional deficits.

Clozapine generally reduces the startle amplitude and enhances baseline PPI in neonatally disrupted rats. More importantly, for the first time, this study reveals that clozapine is a "double-edged sword" in treating attentional deficits: it restores fear conditioning-induced attentional modulation of PPI with loss of the prepulse feature specificity in isolation-reared rats, but not neonatally MK-801 treated rats, and impairs spatial attention modulation of PPI in normally reared rats.

In conclusion, compared to isolation rearing, neonatal exposure to MK-801 causes different central impairments and can be used for improving animal models of schizophrenia.

Acknowledgments This study was supported by the National Clinical Key Construction Project in Chinese Medicine (2100299), the Clinical Characteristics Program of Beijing Municipal Science and Technology Commission (Z151100004015061), the National Natural Science Foundation of China (31470987), and the "985" Project of Peking University.

\section{Compliance with ethical standards}

Conflict of interest The authors declare no conflict of interest.

\section{References}

Abekawa T, Ito K, Nakagawa S, Koyama T (2007) Prenatal exposure to an NMDA receptor antagonist, MK-801 reduces density of parvalbumin-immunoreactive GABAergic neurons in the medial prefrontal cortex and enhances phencyclidine-induced hyperlocomotion but not behavioral sensitization to methamphetamine in postpubertal rats. Psychopathology 192:303-316. doi:10.1007/s00213-007-0729-8

Amitai N, Semenova S, Markou A (2007) Cognitive-disruptive effects of the psychotomimetic phencyclidine and attenuation by atypical antipsychotic medications in rats. Psychopathology 193:521-537. doi:10.1007/s00213-007-0808-x

Andersen RA, Cui H (2009) Intention, action planning, and decision making in parietal-frontal circuits. Neuron 63:568-583. doi:10.1016/j.neuron.2009.08.028

Arndt DL, Johns KC, Dietz ZK, Cain ME (2015) Environmental condition alters amphetamine self-administration: role of the mGluR5 receptor and schedule of reinforcement. Psychopathology 232: 3741-3752. doi:10.1007/s00213-015-4031-x

Auclair AL, Besnard J, Newman-Tancredi A, Depoortère R (2009) The five choice serial reaction time task: comparison between SpragueDawley and Long-Evans rats on acquisition of task, and sensitivity to phencyclidine. Pharmacol Biochem Behav 92:363-369. doi:10.1016/j.pbb.2009.01.005

Ayala JE, Chen Y, Banko JL, Sheffler DJ, Williams R, Telk AN et al (2009) mGluR5 positive allosteric modulators facilitate both hippocampal LTP and LTD and enhance spatial learning. Neuropsychopharmacology 34:2057-2071. doi:10.1038 /npp.2009.30
Bergado-Acosta JR, Sangha S, Narayanan RT, Obata K, Pape HC, Stork $\mathrm{O}$ (2008) Critical role of the $65-\mathrm{kDa}$ isoform of glutamic acid decarboxylase in consolidation and generalization of Pavlovian fear memory. Learn Mem 15:163-171. doi:10.1101/lm.705408

Beninger RJ, Jhamandas A, Aujla H, Xue I, Dagnone RV, Boegman RJ et al (2002) Neonatal exposure to the glutamate receptor antagonist MK-801: effects on locomotor activity and pre-pulse inhibition before and after sexual maturity in rats. Neurotox Res 4:477-488. doi: $10.1080 / 10298420290031414$

Bordi F, LeDoux J (1992) Sensory tuning beyond the sensory system: an initial analysis of auditory response properties of neurons in the lateral amygdaloid nucleus and overlying areas of the striatum. J Neurosci 12:2493-2503

Bourdelais AJ, Deutch AY (1994) The effects of haloperidol and clozapine on extracellular GABA levels in the prefrontal cortex of the rat: an in vivo microdialysis study. Cereb Cortex 4:69-77. doi:10.1093 /cercor/4.1.69

Broberg BV, Dias R, Glenthøj BY, Olsen CK (2008) Evaluation of a neurodevelopmental model of schizophrenia-early postnatal PCP treatment in attentional set-shifting. Behav Brain Res 190:160 163. doi:10.1016/j.bbr.2008.02.020

Broberg BV, Glenthøj BY, Dias R, Larsen DB, Olsen CK (2009) Reversal of cognitive deficits by an ampakine (CX516) and sertindole in two animal models of schizophrenia-sub-chronic and early postnatal PCP treatment in attentional set-shifting. Psychopathology 206: 631-640. doi:10.1007/s00213-009-1540-5

Buuse M, Garner B, Koch M (2003) Neurodevelopmental animal models of schizophrenia: effects on prepulse inhibition. Curr Mol Med 3: 459-471. doi:10.2174/1566524033479627

Dalmaso M, Galfano G, Tarqui L, Forti B, Castelli L (2013) Is social attention impaired in schizophrenia? Gaze, but not pointing gestures, is associated with spatial attention deficits. Neuropsychology 27: 608-613. doi:10.1037/a0033518

Du Y, Li J, Wu X, Li L (2009) Precedence-effect-induced enhancement of prepulse inhibition in socially reared but not isolation-reared rats. Cogn Affect Behav Neurosci 9:44-58. doi:10.3758/CABN.9.1.44

Du Y, Wu X, Li L (2010) Emotional learning enhances stimulus-specific top-down modulation of sensorimotor gating in socially reared rats but not isolation-reared rats. Behav Brain Res 206:192-201. doi:10.1016/j.bbr.2009.09.012

Du Y, Wu X, Li L (2011) Differentially organized top-down modulation of prepulse inhibition of startle. J Neurosci 31:13644-13653. doi:10.1523/JNEUROSCI.1292-11.2011

Du Y, Wang Q, Zhang Y, Wu XH, Li L (2012) Perceived target-masker separation unmasks responses of lateral amygdala to the emotionally conditioned target sounds in awake rats. Neuroscience 225:249 257. doi:10.1016/j.neuroscience.2012.08.022

Farnbach-Pralong D, Bradbury R, Copolov D, Dean B (1998) Clozapine and olanzapine treatment decreases rat cortical and limbic GABA(A) receptors. Eur J Pharmacol 349:7-8

Fendt M, Li L, Yeomans JS (2001) Brainstem circuits mediating prepulse inhibition of the startle reflex. Psychopathology 156:216-224. doi: $10.1007 / \mathrm{s} 002130100794$

Fowler SW, Walker JM, Klakotskaia D, Will MJ, Serfozo P, Simonyi A et al (2013) Effects of a metabotropic glutamate receptor 5 positive allosteric modulator, CDPPB, on spatial learning task performance in rodents. Neurobiol Learn Mem 99:25-31. doi:10.1016/j. nlm.2012.10.010

Freyman RL, Helfer KS, McCall DD, Clifton RK (1999) The role of perceived spatial separation in the unmasking of speech. J Acoust Soc Am 106:3578-3588. doi:10.1121/1.428211

Frogley C, Taylor D, Dickens G, Picchioni M (2012) A systematic review of the evidence of clozapine's anti-aggressive effects. Int J Neuropsychopharmacol 15:1351-1371. doi:10.1017 /S146114571100201X 
Geyer MA, Krebs-Thomson K, Braff DL, Swerdlow NR (2001) Pharmacological studies of prepulse inhibition models of sensorimotor gating deficits in schizophrenia: a decade in review. Psychopathology 156:117-154. doi:10.1007/s002130100811

Gilland E, Bona E, Levene M, Hagberg H (1997) Magnesium and the Nmethyl-D-aspartate receptor antagonist dizocilpine maleate neither increase glucose use nor induce a 72-kilodalton heat shock protein expression in the immature rat brain. Pediatr Res 42:472-477. doi:10.1203/00006450-199710000-00008

Hansen HH, Briem T, Dzietko M, Sifringer M, Voss A, Rzeski W et al (2004) Mechanisms leading to disseminated apoptosis following NMDA receptor blockade in the developing rat brain. Neurobiol Dis 16:440-453. doi:10.1016/j.nbd.2004.03.013

Hazlett EA, Romero MJ, Haznedar MM, New AS, Goldstein KE, Newmark RE et al (2007) Deficient attentional modulation of startle eyeblink is associated with symptom severity in the schizophrenia spectrum. Schizophr Res 93:288-295. doi:10.1016/j. schres.2007.03.012

Heidbreder CA, Foxton R, Cilia J, Hughes ZA, Shah AJ, Atkins A, Hunter JA et al (2001) Increased responsiveness of dopamine to atypical, but not typical antipsychotics in the medial prefrontal cortex of rats reared in isolation. Psychopathology 156:338-351. doi:10.1007/s002130100760

Houthoofd SA, Morrens M, Sabbe BG (2008) Cognitive and psychomotor effects of risperidone in schizophrenia and schizoaffective disorder. Clin Ther 30:1565-1589. doi:10.1016/j.clinthera.2008.09.014

Huang EJ, Reichardt LF (2003) Trk receptors: roles in neuronal signal transduction. Annu Rev Biochem 72:609-642

Huang J, Wu X, Yeomans J, Li L (2005) Opposite effects of tetanic stimulation of the auditory thalamus or auditory cortex on the acoustic startle reflex in awake rats. Eur J Neurosci 21:1943-1956. doi:10.1111/j.1460-9568.2005.04030.x

Ikonomidou C, Bosch F, Miksa M, Bittigau P, Vöckler J, Dikranian K et al (1999) Blockade of NMDA receptors and apoptotic neurodegeneration in the developing brain. Science 283:70-74. doi:10.1126 /science. 283.5398.70

Ison JR, Hammond GR (1971) Modification of the startle reflex in rat by changes in the auditory and visual environments. J Comp Physiol Psychol 75:452. doi:10.1037/h0030934

Jantas D, Lason W (2009) Different mechanisms of NMDA-mediated protection against neuronal apoptosis: a stimuli-dependent effect. Neurochem Res 34:2040-2054. doi:10.1007/s11064-009-9991-y

Jia Z, Lu Y, Henderson J, Taverna F, Romano C, Abramow-Newerly W et al (1998) Selective abolition of the NMDA component of long-term potentiation in mice lacking mGluR5. Learn Mem 5:331-343. doi:10.1101/lm.5.4.331

Kang H, Schuman EM (1995) Long-lasting neurotrophin-induced enhancement of synaptic transmission in the adult hippocampus. Science 267:1658-1662. doi:10.1126/science.7886457

Kanungo AK, Liadis N, Robertson J, Woo M, Henderson JT (2009) Excitatory tonus is required for the survival of granule cell precursors during postnatal development within the cerebellum. Neuroscience 158:1364-1377. doi:10.1016/j.neuroscience.2008.10.062

Kaplan DR, Miller FD (2000) Neurotrophin signal transduction in the nervous system. Curr Opin Neurobiol 10:381-391. doi:10.1016 /S0959-4388(00)00092-1

Karkhanis AN, Alexander NJ, McCool BA, Weiner JL, Jones SR (2015) Chronic social isolation during adolescence augments catecholamine response to acute ethanol in the basolateral amygdala. Synapse 69:385-395. doi:10.1002/syn.21826

Kelly JB, Masterton B (1977) Auditory sensitivity of the albino rat. J Comp Physiol Psychol 91:930-936

Kelly JB, Sally SL (1988) Organization of auditory cortex in the albino rat: binaural response properties. J Neurophysiol 59:1756-1769

Koike H, Ibi D, Mizoguchi H, Nagai T, Nitta A, Takuma K et al (2009) Behavioral abnormality and pharmacologic response in social isolation-reared mice. Behav Brain Res 202:114-121. doi:10.1016 j.bbr.2009.03.028

Komuro H, Rakic P (1993) Modulation of neuronal migration by NMDA receptors. Science 260:95-97. doi:10.1126/science.8096653

Le Pen G, Moreau JL (2002) Disruption of prepulse inhibition of startle reflex in a neurodevelopmental model of schizophrenia: reversal by clozapine, olanzapine and risperidone but not by haloperidol. Neuropsychopharmacology 27:1-11. doi:10.1016/S0893-133X(01 )00383-9

Le Pen G, Grottick AJ, Higgins GA, Moreau JL (2003) Phencyclidine exacerbates attentional deficits in a neurodevelopmental rat model of schizophrenia. Neuropsychopharmacology 28:1799-1809. doi:10.1038/sj.npp.1300208

Lei M, Luo L, Qu T, Jia H, Li L (2014) Perceived location specificity in perceptual separation-induced but not fear conditioning-induced enhancement of prepulse inhibition in rats. Behav Brain Res 269:8794. doi:10.1016/j.bbr.2014.04.030

Leng A, Feldon J, Ferger B (2004) Long-term social isolation and medial prefrontal cortex: dopaminergic and cholinergic neurotransmission. Pharmacol Biochem Behav 77:371-379. doi:10.1016/j. pbb.2003.11.011

Li JT, Zhao YY, Wang HL, Wang XD, Su YA, Si TM (2015) Long-term effects of neonatal exposure to MK-801 on recognition memory and excitatory-inhibitory balance in rat hippocampus. Neuroscience 308:134-143. doi:10.1016/j.neuroscience.2015.09.003

Li L, Frost BJ (2000) Azimuthal directional sensitivity of prepulse inhibition of the pinna startle reflex in decerebrate rats. Brain Res Bull 51:95-100. doi:10.1016/S0361-9230(99)00215-4

Li L, Shao J (1998) Restricted lesions to ventral prefrontal subareas block reversal learning but not visual discrimination learning in rats. Physiol Behav 65:371-379. doi:10.1016/S0031-9384(98)00216-9

Li L, Daneman M, Qi GQ, Schneider BA (2004) Does the information content of an irrelevant source differentially affect speech recognition in younger and older adults? J Exp Psychol Hum Percept Perform 30:1077-1091. doi:10.1037/0096-1523.30.6.1077

Li L, Qi JG, He Y, Alain C, Schneider BA (2005) Attribute capture in the precedence effect for long-duration noise sounds. Hear Res 202: 235-247. doi:10.1016/j.heares.2004.10.007

Li L, Du Y, Li N, Wu X, Wu Y (2009) Top-down modulation of prepulse inhibition of the startle reflex in humans and rats. Neurosci Biobehav Rev 33:1157-1167. doi:10.1016/j.neubiorev.2009.02.001

Li N, Wu X, Li L (2007) Chronic administration of clozapine alleviates reversal-learning impairment in isolation-reared rats. Behav Pharmacol 18:135-145. doi:10.1097/FBP.0b013e3280d3ee83

Lim AL, Taylor DA, Malone DT (2012a) Consequences of early life MK801 administration: long-term behavioural effects and relevance to schizophrenia research. Behav Brain Res 227:276-286. doi:10.1016 /j.bbr.2011.10.052

Lim AL, Taylor DA, Malone DT (2012b) A two-hit model: behavioural investigation of the effect of combined neonatal MK-801 administration and isolation rearing in the rat. J Psychopharmacol 26:12521264. doi: $10.1177 / 0269881111430751$

Litovsky RY, Colburn HS, Yost WA, Guzman SJ (1999) The precedence effect. J Acoust Soc Am 106:1633-1654. doi:10.1121/1.427914

Liu H, Ren Z, Zhong J, Cai H, Chen X, Li J (2014) Haloperidol and clozapine reverse MK-801-induced deficits in hypoactivity, but not the impairment of spatial memory in Sprague-Dawley rats. Int $\mathbf{J}$ Pharmacol 10:120-128. doi:10.3923/ijp.2014.120.128

Luz M, Mohr E, Fibiger HC (2016) GDNF-induced cerebellar toxicity: a brief review. Neurotoxicology 52:46-56. doi:10.1016/j. neuro.2015.10.011

Manning SM, Boll G, Fitzgerald E, Selip DB, Volpe JJ, Jensen FE (2011) The clinically available NMDA receptor antagonist, memantine, exhibits relative safety in the developing rat brain. Int $J$ Dev Neurosci 29:767-773. doi:10.1016/j.ijdevneu.2011.05.005 
McLean SL, Grayson B, Harris M, Protheroe C, Woolley ML, Neill JC (2010) Isolation rearing impairs novel object recognition and attentional set shifting performance in female rats. J Psychopharmacol 24:57-63. doi:10.1177/0269881108093842

Melendez RI, Gregory ML, Bardo MT, Kalivas PW (2004) Impoverished rearing environment alters metabotropic glutamate receptor expression and function in the prefrontal cortex. Neuropsychopharmacology 29: 1980-1987. doi:10.1038/sj.npp.1300507

Meltzer HY, McGurk SR (1999) The effects of clozapine, risperidone, and olanzapine on cognitive function in schizophrenia. Schizophr Bull 25:233-256. doi:10.1093/oxfordjournals.schbul.a033376

Möller M, Du Preez JL, Emsley R, Harvey BH (2011) Isolation rearinginduced deficits in sensorimotor gating and social interaction in rats are related to cortico-striatal oxidative stress, and reversed by subchronic clozapine administration. Eur Neuropsychopharmacol 21: 471-483. doi:10.1016/j.euroneuro.2010.09.006

Möller M, Du Preez JL, Viljoen FP, Berk M, Emsley R, Harvey BH (2013) Social isolation rearing induces mitochondrial, immunological, neurochemical and behavioural deficits in rats, and is reversed by clozapine or N-acetyl cysteine. Brain Behav Immun 30:156-167. doi:10.1016/j.bbi.2012.12.011

Nozari M, Shabani M, Farhangi AM, Mazhari S, Atapour N (2015) Sexspecific restoration of MK-801-induced sensorimotor gating deficit by environmental enrichment. Neuroscience 299:28-34. doi:10.1016/j.neuroscience.2015.04.050

O'Connor WT, O'Shea SD (2015) Clozapine and GABA transmission in schizophrenia disease models: establishing principles to guide treatments. Pharmacol Ther 150:47-80. doi:10.1016/j. pharmthera.2015.01.005

Okada R, Matsumoto K, Tsushima R, Fujiwara H, Tsuneyama K (2014) Social isolation stress-induced fear memory deficit is mediated by down-regulated neuro-signaling system and Egr-1 expression in the brain. Neurochem Res 39:875-882. doi:10.1007/s11064-014-1283-5

Otoya RE, Seltzer AM, Donoso AO (1997) Acute and long-lasting effects of neonatal hypoxia on (+)-3-[ $\left[{ }^{125} \mathrm{I}\right] \mathrm{MK}-801$ binding to NMDA brain receptors. Exp Neurol 148:92-99. doi:10.1006/exnr.1997.6612

Palmer MJ, Irving AJ, Seabrook GR, Jane DE, Collingridge GL (1997) The group I mGlu receptor agonist DHPG induces a novel form of LTD in the CA1 region of the hippocampus. Neuropharmacology 36:1517-1532. doi:10.1016/S0028-3908(97)00181-0

Piantadosi PT, Floresco SB (2014) Prefrontal cortical GABA transmission modulates discrimination and latent inhibition of conditioned fear: relevance for schizophrenia. Neuropsychopharmacology 39: 2473-2484. doi:10.1038/npp.2014.929

Reep RL, Chandler HC, King V, Corwin JV (1994) Rat posterior parietal cortex: topography of corticocortical and thalamic connections. Exp Brain Res 100:67-84. doi:10.1007/BF00227280

Romanski LM, LeDoux JE (1993) Information cascade from primary auditory-cortex to the amygdala-corticocortical and corticoamygdaloid projections of temporal cortex in the rat. Cereb Cortex 3:515-532. doi:10.1093/cercor/3.6.515

Sebban C, Tesolin-Decros B, Ciprian-Ollivier J, Perret L, Spedding M (2002) Effects of phencyclidine (PCP) and MK 801 on the EEGq in the prefrontal cortex of conscious rats; antagonism by clozapine, and antagonists of AMPA-, $\alpha 1$ - and 5-HT2A-receptors. Br J Pharmacol 135:65-78. doi:10.1038/sj.bjp.0704451

Semenova S, Markou A (2007) The effects of the mGluR5 antagonist MPEP and the mGluR2/3 antagonist LY341495 on rats' performance in the 5-choice serial reaction time task. Neuropharmacology 52: 863872. doi:10.1016/j.neuropharm.2006.10.003
Spagna A, Dong Y, Mackie MA, Li M, Harvey PD, Tian Y (2015) Clozapine improves the orienting of attention in schizophrenia. Schizophr Res 168:285-291. doi:10.1016/j.schres.2015.08.009

Strauss GP, Llerena K, Gold JM (2011) Attentional disengagement from emotional stimuli in schizophrenia. Schizophr Res 131:219-223. doi:10.1016/j.schres.2011.06.001

Swart M, Liemburg EJ, Kortekaas R, Wiersma D, Bruggeman R, Aleman A (2013) Normal brain activation in schizophrenia patients during associative emotional learning. Psychiatry Res Neuroimaging 214: 269-276. doi:10.1016/j.pscychresns.2013.08.008

Taylor SF, Demeter E, Phan KL, Tso IF, Welsh RC (2014) Abnormal GABAergic function and negative affect in schizophrenia. Neuropsychopharmacology 39:1000-1008. doi:10.1038 /npp.2013.300

Terry AV, Schade R, Callahan PM, Chapman JM, Bartlett MG (2011) Chronic treatment with nicotine metabolite, cotinine, improves sustained attention and recognition memory in rats and attenuates glutamate (NMDA) antagonist-related impairments. Biochem Pharmacol 82:1041-1042. doi:10.1016/j.bcp.2011.07.048

Tso IF, Fang Y, Phan KL, Welsh RC, Taylor SF (2015) Abnormal GABAergic function and face processing in schizophrenia: a pharmacologic-fMRI study. Schizophr Res 168:338-344. doi:10.1016/j.schres.2015.08.022

Uehara T, Sumiyoshi T, Seo T, Itoh H, Matsuoka T, Suzuki M et al (2009) Long-term effects of neonatal MK-801 treatment on prepulse inhibition in young adult rats. Psychopathology 206:623-630. doi:10.1007/s00213-009-1527-2

Uehara T, Sumiyoshi T, Seo T, Matsuoka T, Itoh H, Suzuki M et al (2010) Neonatal exposure to MK-801, an N-methyl-D-aspartate receptor antagonist, enhances methamphetamine-induced locomotion and disrupts sensorimotor gating in pre- and post-pubertal rats. Brain Res 1352:223-230. doi:10.1016/j.brainres.2010.07.013

Uehara T, Sumiyoshi T, Hattori H, Itoh $\mathrm{H}$, Matsuoka T, Iwakami $\mathrm{N}$ et al (2012) T-817MA, a novel neurotrophic agent, ameliorates loss of GABAergic parvalbumin-positive neurons and sensorimotor gating deficits in rats transiently exposed to MK-801 in the neonatal period. J Psychiatr Res 46:622-629. doi:10.1016/j.jpsychires.2012.01.022

Uehara T, Sumiyoshi T, Rujescu D, Genius J, Matsuoka T, Takasaki I et al (2014) Neonatal exposure to MK-801 reduces mRNA expression of mGlu3 receptors in the medial prefrontal cortex of adolescent rats. Synapse 68:202-208. doi:10.1002/syn.21734

Usiello A, Sargolini F, Roullet P, Ammassari-Teule M, Passino E, Oliverio A et al (1998) N-Methyl-D-aspartate receptors in the nucleus accumbens are involved in detection of spatial novelty in mice. Psychopathology 137:175-183. doi:10.12007/s002130050607

Weiss IC, Di IL, Feldon J, Domeney AM (2000) Strain differences in the isolation-induced effects on prepulse inhibition of the acoustic startle response and on locomotor activity. Behav Neurosci 114:364. doi:10.1037//0735.7044.114.2.364

Wilson MA, Kinsman SL, Johnston MV (1998) Expression of NMDA receptor subunit mRNA after MK-801 treatment in neonatal rats. Dev Brain Res 109:211-220. doi:10.1016 /S0165-3806(98)00084-4

Zheng Y, Wu C, Li J, Wu H, She S, Liu S et al (2015) Brain substrates of perceived spatial separation between speech sources under simulated reverberant listening conditions in schizophrenia. Psychol Med 46:477-491. doi:10.1017/S0033291715001828

Zou D, Huang J, Wu X, Li L (2007) Metabotropic glutamate subtype 5 receptors modulate fear-conditioning induced enhancement of prepulse inhibition in rats. Neuropharmacology 52:476-486. doi:10.1016/j.neuropharm.2006.08.016 